\title{
Radiation exposure in patients undergoing procedural interventions for pain relief
}

\section{Dr M Misurati , Dr B Rajdev , Dr A Puttapa}

- An increase in the number of procedures performed for pain management

- Large proportion of patients are subjected to higher and repeated exposure to radiation with resultant cumulative doses

- There is no National Guidelines for Pain procedures and Radiation Exposure

\section{Aim}

- Investigate the radiation exposure to patients undergoing Lumbar medial branch blocks

- Measure radiation parameters

- Screening time

- Dose area product (DAP) values

- Find variation in practice between consultants

- To compare with the published data (reference level)

\section{Standard}

Lumbar medial branch blocks (Lichtherte $S$ et

al)

- DAP - $2.5 \mathrm{~Gy} . \mathrm{cm}^{2}$

- Screening time - $60 \mathrm{sec}$

- Lack of national or local guidelines for maximum allowable radiation exposure for common pain intervention procedures

\section{Method}

Retrospective Study

Royal stoke and County Hospital, Stafford

Last 6 months

5 consultants $(A, B, C, D, E)$

Study Bilateral L3, L4, L5 MBB

3 consultants- 10 patients each

2 consultants- 5 patients each

\section{Results \\ Screening time $<60$ seconds in all patients DAP $<2.5 \mathrm{~Gy} . \mathrm{cm}^{2}$ in 32 patients \\ $\mathrm{DAP}>2.5 \mathrm{~Gy} . \mathrm{cm}^{2}$ in 8 patients}
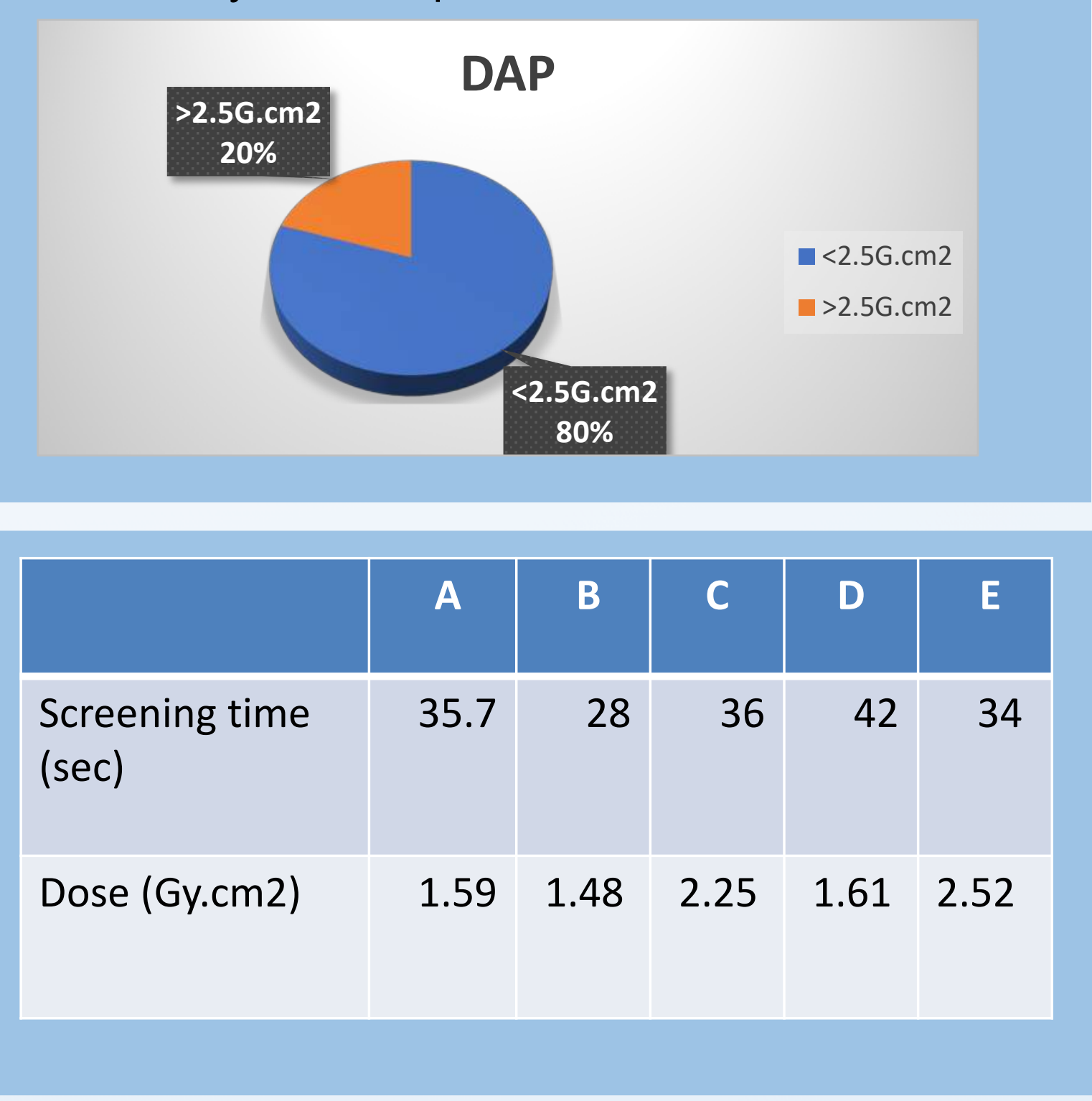

\section{Confounding Factors}

- Patients

- Not adjusted for Age, Sex, BMI

- Consultants

-Sample size variation

-Variation in technique

- Different sites :

Different $X$ ray machines

\section{Recommendations}

- Balance risks of radiation to benefits of Pain relief

- Limit radiation exposure ( screening times and DAP ) to mentioned reference values

- Aim for local guidance (liaise with radiologist) until national guidelines available

1. Hanu Cernat D, Duarte R, Raphael JH, Mutagi H, Kapur S, Senthil L. Type of interventional pain procedure, body weight and presence of spinal pathology are determinants of the level of radiation exposure for fluoroscopically guided pain procedures. Pain Practice 2012 